\title{
Effect of machining process on surface microhardness of titanium carbide reinforced aluminium LM6 composite
}

\begin{abstract}
Due to the fact that material is being removed from the bulk material, all machining operations have some impact on the resulting surface integrity of the machined components. This paper presents an investigation on surface microhardness on machining of $\mathrm{TiC}$ reinforced aluminium LM6 alloy composite using uncoated carbide tool under dry cutting condition. The experiments that were carried out consisted of different cutting parameters based on combination of cutting speed, feed and depth of cut as the parameters of cutting process. The microhardness of machined surface at a range of cutting speed, feed and depth of cut were measured. The results show that the microhardness was generally found to be higher near the machined surface layer than the hardness of the matrix in the bulk material during machining for all cutting condition. Microhardness increases beyond the bulk hardness of material occurred $50 \mathrm{\varepsilon m}$ below machined surface, and then microhardness starts to decrease and reaches the bulk hardness. The microhardness values increases with increased the feed and depth of cut. The highest microhardness recorded was 68 HV0.5 when

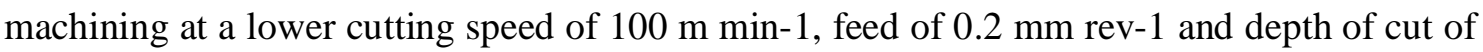
$1.0 \mathrm{~mm}$.
\end{abstract}

Keyword: Cutting parameter; LM6-TIC composite; Machined surface; Microhardness 